\title{
Hydrogen peroxide sensing based on carbon quantum dots
}

\author{
Cheng-Shane Chu , Meng-Wei Hsieh and Zhi-Ren Su \\ Ming Chi University of Technology, 24301 New Taipei City, Taiwan
}

\begin{abstract}
In this work, carbon quantum dots (CQDs) have been synthesized by one step hydrothermal method to detect hydrogen peroxide $\left(\mathrm{H}_{2} \mathrm{O}_{2}\right)$. The optical $\mathrm{H}_{2} \mathrm{O}_{2}$ sensors were based on the fluorescent quenching of the carbon quantum dots. The optical $\mathrm{H}_{2} \mathrm{O}_{2}$ sensors demonstrate capable of detecting $\mathrm{H}_{2} \mathrm{O}_{2}$ over the range of 0-88.2 $\mathrm{mM}$ and 0-60 $\mathrm{mM}$. The $\mathrm{H}_{2} \mathrm{O}_{2}$ sensitivities of wavelength shift to changes in the $\mathrm{H}_{2} \mathrm{O}_{2}$ concentration were found to be $0.18 \mathrm{~nm} / \mathrm{mM}$ and $0.26 \mathrm{~nm} / \mathrm{mM}$. These results of the optical sensors showed that the method can be used in practice detection of $\mathrm{H}_{2} \mathrm{O}_{2}$ and could offer a new approach for developing a new optical biosensor. The CQDs exhibit good emission property and high stability, as well as excitation-independent emission behavior. Moreover, it is attractive that CQDs can be used as an effective fluorescent probe for the detection of $\mathrm{H}_{2} \mathrm{O}_{2}$ with linear Stern-Volmer plot and wavelength shift in an aqueous solution.
\end{abstract}

\section{Introduction}

Hydrogen peroxide $\left(\mathrm{H}_{2} \mathrm{O}_{2}\right)$ plays an essential role as an oxidizing, bleaching and sterilizing agent in biochemical and chemical industry [1]. High concentrations of $\mathrm{H}_{2} \mathrm{O}_{2}$ would cause irritation to dyes and shin, it affects human health [2]. On the other hand, the determination of $\mathrm{H}_{2} \mathrm{O}_{2}$ concentration is important in food [3], clinical [4] and environmental applications [5]. There are many methods which can be used for the quantitative analysis of $\mathrm{H}_{2} \mathrm{O}_{2}$ in solution, such as electrochemical method [6] and spectroscopy [7-12]. The electrochemical methods are well suited determining lower concentrations of $\mathrm{H}_{2} \mathrm{O}_{2}$, however, they can suffer interference from other reactive oxygen species. Furthermore, electrochemical detection methods are all susceptible in the environment with significant electromagnetic interference. On the other hand, the field of spectroscopic detection method can be subdivided into chemiluminescence [7-10], and spectrofluorometry $[2,11]$. The spectroscopic techniques can also be used for detection of $\mathrm{H}_{2} \mathrm{O}_{2}$ at low concentrations. The spectroscopic techniques have been integrated with luminescent quantum dots (QDs), making possible the development of optical sensors with high sensitivity and many of advantages of luminescent QDs, such as small size, high selectivity and immunity to electromagnetic interference.

In the last decade, there has been a focus on the luminescent carbon quantum dots (CQDs) to further improve the optical sensing technique due to their unique optical properties caused by the quantum confinement effect. The luminescent carbon quantum dots (CQDs) were first produced in 2006 [12]. Compare to semiconductor quantum dots, luminescent CQDs were considered as a brand new class of luminescent due to their small size, high quantum yield, low cytotoxicity, possess fine biocompatibility, high photostability and environment friendliness, which make them suitable chemical and biological analyses. There are several methods to prepare CQDs have been reported [13-17]. However, these methods usually require not only complicated equipment and expensive materials but also complicated post treatment to enhance the quantum yield and water solubility of CQDs. Meanwhile, the isolation, purification and functionalization processes based on these methods are all complicated and time consuming. Therefore, the hydrothermal method has been widely used to prepare various luminescent QDs because of the high reactivity of the reactants, easy control of the solution, low level of air pollution and low energy consumption under hydrothermal conditions [18].

In this work, we have presented a new and simple $\mathrm{H}_{2} \mathrm{O}_{2}$ detecting method based on the fluorescence quenching and wavelength shift of CQDs. Fluorescence quenching refers to any process which decreases the fluorescence intensity of a certain fluorophore due to various molecular interactions. The optical sensor was composed of CQDs without any complex processes of functionalization or conjugation. The obtained optical biosensor showed the linear detection range and wavelength shift. The sensitivity enables the use of the QDs as $\mathrm{H}_{2} \mathrm{O}_{2}$ sensors and provides a versatile fluorescent reporter for the activities of oxidases and for the detection of their substrate.

\section{Experiments}




\subsection{Synthesis of CQDs}

All reagents used were of analytical grade without further purification. The CQDs were synthesized from sodium citrate through a simple, convenient and one-step hydrothermal method. Briefly, sodium citrate $(0.3 \mathrm{~g})$, $\mathrm{NH}_{4} \mathrm{HCO}_{3}(3.1 \mathrm{~g})$ and water $(20 \mathrm{~mL})$ were sealed into a Teflon equipped stainless steel autoclave, which was then placed in a drying oven followed by hydrothermal treatment at varying temperatures for $4 \mathrm{~h}$. After the reaction, the autoclave was cooled to room temperature. The purification of the CQDs was conducted through a dialysis tube for about $24 \mathrm{~h}$ in dark.

Figure 1 (a) shows a TEM image of the CQDs. From inspection, the average diameter of the QDs is $5 \mathrm{~nm}$. Figure 1(b) presents the energy-dispersive X-ray spectroscopy (EDX) results for the composition of the CQDs. The nanoparticles are composed principally of $\mathrm{O}$, $\mathrm{C}$, and $\mathrm{Cu}$ elements, where the $\mathrm{x}$ axis represents energy $(\mathrm{keV})$ and the $\mathrm{y}$ axis represents the counts per second per electron (basically X-ray intensity). The $\mathrm{Cu}$ content originates from the copper grid, the $\mathrm{C}$ content originates from the CQDs.

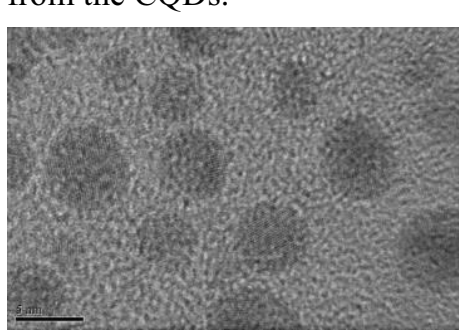

(a)

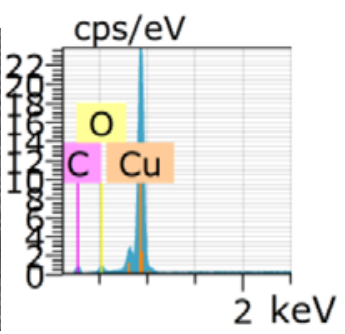

(b)
Fig. 1 (a)TEM image showing CQDs at a resolution of $5 \mathrm{~nm}$ (b) EDX analysis results for CQDs.

\subsection{Instrumentation}

Figure 2 shows a schematic illustration of the experimental arrangement used to characterize the performance of the optical $\mathrm{H}_{2} \mathrm{O}_{2}$ sensors. In the sensing experiments, the fluorescence excitation was provided by an LED (NSHU591B, NICHIA, COPR.) with a central wavelength of $365 \mathrm{~nm}$ driven by an arbitrary waveform generator (TGA1240, Thurlby Thandar Instruments (TTI) Ltd.) at $10 \mathrm{kHz}$ in pulse signal mode. The emission measurements were acquired using a USB 4000 spectrometer (Ocean Optics).

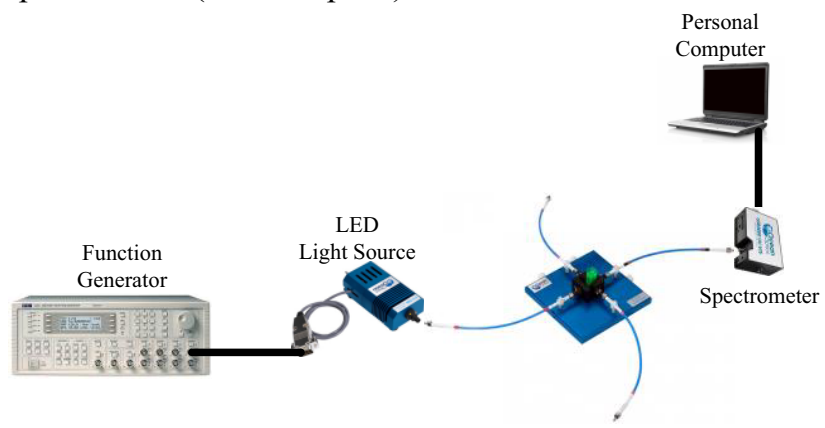

Fig. 2 Schematic diagram showing experimental arrangement used for characterization.

\section{Results and Disscussion}

\subsection{Optical $\mathrm{H}_{2} \mathrm{O}_{2}$ sensing properties}

Figures 3 (a) and (b) present the room-temperature fluorescence spectra of the optical $\mathrm{H}_{2} \mathrm{O}_{2}$ sensors under $\mathrm{H}_{2} \mathrm{O}_{2}$ concentrations ranging from $0-88$ and $0-60 \mathrm{mM}$, respectively. Note that in acquiring the relative fluorescence intensity data, the integration time of the CCD spectrometer was set at $10 \mathrm{~ms}$, and as a result, the optical $\mathrm{H}_{2} \mathrm{O}_{2}$ sensors exhibit strong fluorescent emissions at $604 \mathrm{~nm}$ and $570 \mathrm{~nm}$. Figure 3 shows that the relative fluorescence intensity of the optical $\mathrm{H}_{2} \mathrm{O}_{2}$ sensors decreases significantly as the $\mathrm{H}_{2} \mathrm{O}_{2}$ concentration increases.

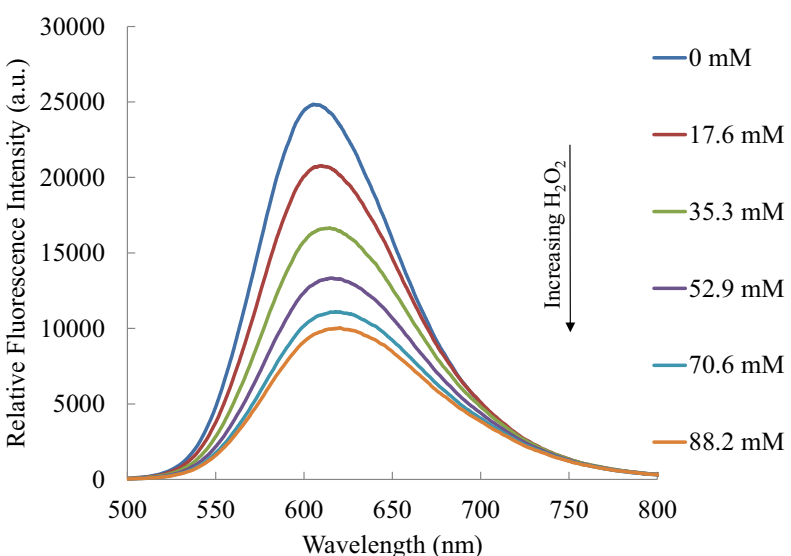

(a)

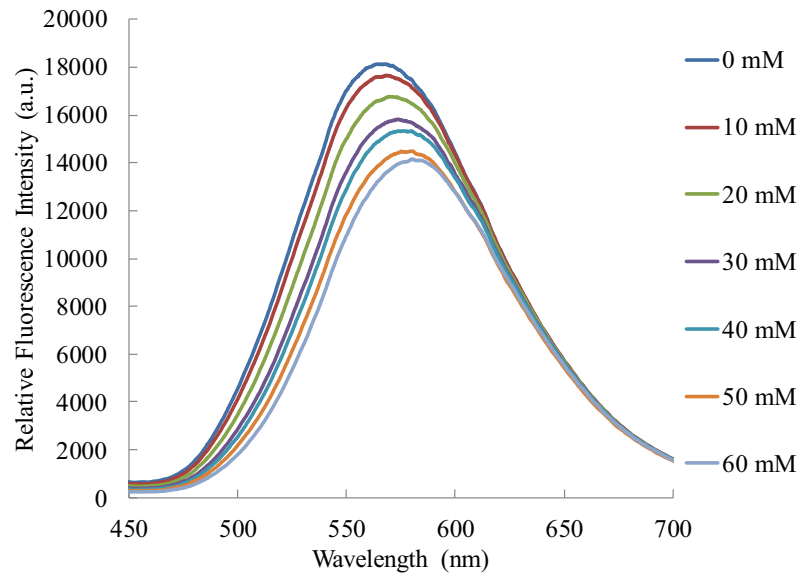

(b)

Fig. 3 Emission spectra of optical sensors under different $\mathrm{H} 2 \mathrm{O} 2$ concentrations: (a) red emission, (b) yellow emission.

The calibration curves of optical $\mathrm{H}_{2} \mathrm{O}_{2}$ sensors were shown in Fig. 4. It is seen that the fluorescence intensity reduces exponentially as the $\mathrm{H}_{2} \mathrm{O}_{2}$ concentration increased. In other words, the fluorescence intensity is reduced as a result $\mathrm{H}_{2} \mathrm{O}_{2}$ quenching. The quenching effect can be described by the Stern-Volmer equation [19]:

$$
I_{0} / I=1+K_{\mathrm{SV}}[Q]
$$

where $I_{0}$ and $I$ represent the steady-state fluorescence intensities in the absence and presence of $\mathrm{H}_{2} \mathrm{O}_{2}$, 
respectively; $K_{\mathrm{SV}}$ is the Stern-Volmer quenching constant; $[Q]$ represents the concentration of quencher $\left(\mathrm{H}_{2} \mathrm{O}_{2}\right)$. $\mathrm{H}_{2} \mathrm{O}_{2}$ is a good quencher for the CQDs and from the Stern-Volmer plot, the concentration of $\mathrm{H}_{2} \mathrm{O}_{2}$ could be estimated.

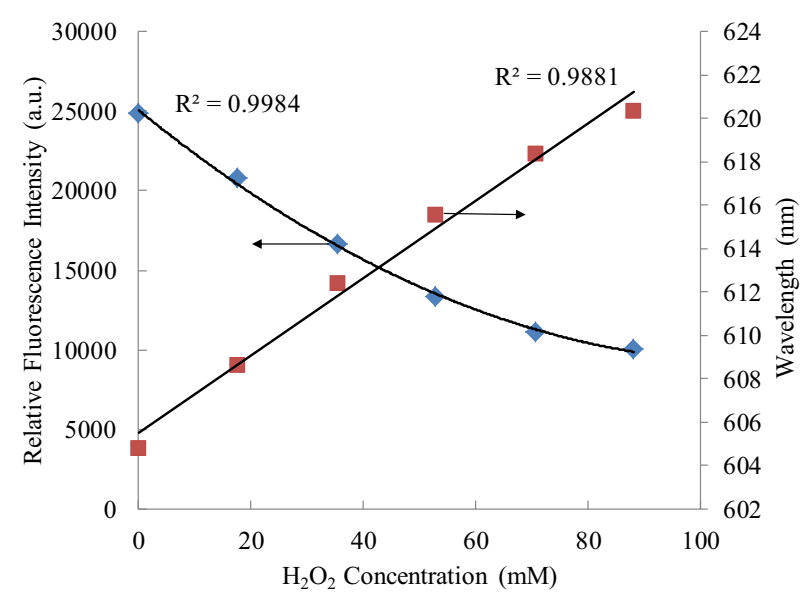

(a)

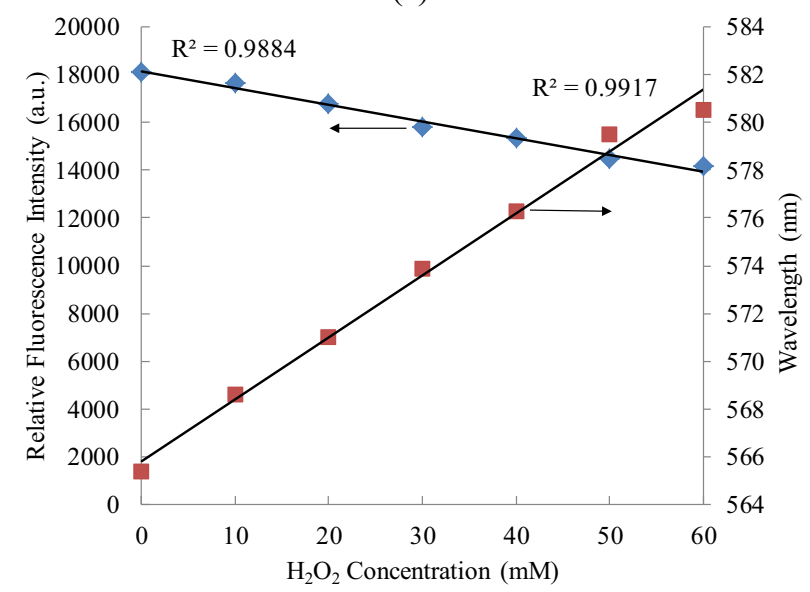

(b)

Fig. 4 Calibration curves of optical $\mathrm{H} 2 \mathrm{O} 2$ sensors: (a) red emission, (b) yellow emission.

Figures 5 have been shown that the peak emission wavelength of CQDs, have a linear dependence on $\mathrm{H} 2 \mathrm{O} 2$ concentration in the environmental range. It can be seen that the peak emission wavelength increases linearly as the $\mathrm{H} 2 \mathrm{O} 2$ concentration increase. The peak wavelength, on the other hand, is shifted towards longer wavelengths. Either effect can be used to obtain $\mathrm{H} 2 \mathrm{O} 2$ concentration information. The optical $\mathrm{H} 2 \mathrm{O} 2$ sensors demonstrate capable of detecting $\mathrm{H} 2 \mathrm{O} 2$ over the range of $0-88.2 \mathrm{mM}$ and $0-60 \mathrm{mM}$, the wavelength shift to changes in the $\mathrm{H} 2 \mathrm{O} 2$ concentration were found to be $0.18 \mathrm{~nm} / \mathrm{mM}$ and $0.26 \mathrm{~nm} / \mathrm{mM}$, respectively. However, simple fluorescence intensity measurements are prone to error due to optical power fluctuations. Due to the presence of a wavelength shift is proportional to $\mathrm{H} 2 \mathrm{O} 2$ concentration and independent of system optical power level.

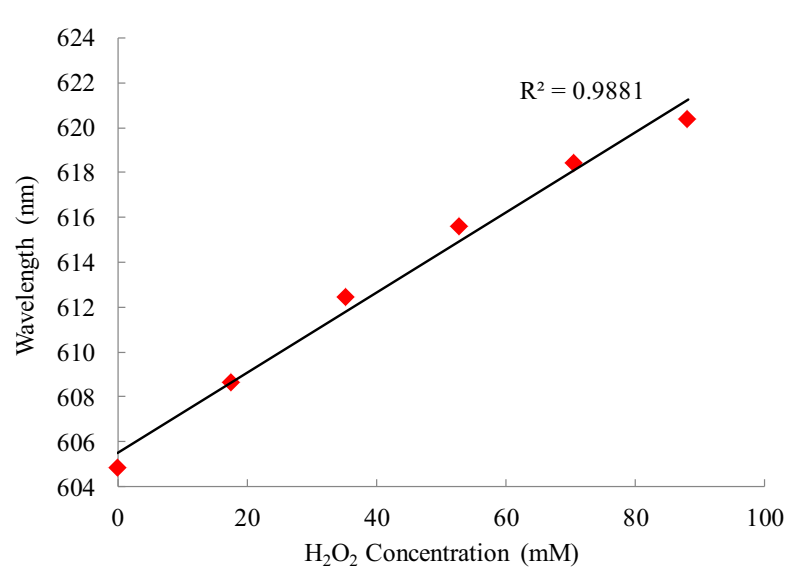

(a)

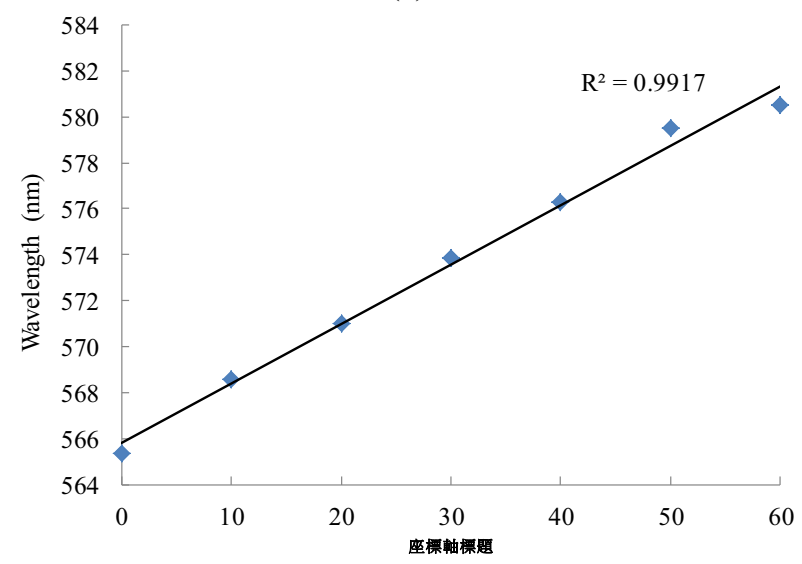

(b)

Fig. 4 Variation of peak emission wavelength with $\mathrm{H} 2 \mathrm{O} 2$ concentration: (a) red emission, (b) yellow emission.

\section{Conclusions}

In this study, we synthesized water-soluble luminescent CQDs by one step hydrothermal method using a common carbon resource. The luminescent CQDs have been successfully applied to develop new fluorescent biosensors for sensitive detection of $\mathrm{H}_{2} \mathrm{O}_{2}$. The resulting sensors exhibited the linear Stern-Volmer plots for the determination of $\mathrm{H}_{2} \mathrm{O}_{2}$. The $\mathrm{H}_{2} \mathrm{O}_{2}$ sensitivities of wavelength shift to changes in the $\mathrm{H}_{2} \mathrm{O}_{2}$ concentration were found to be $0.18 \mathrm{~nm} / \mathrm{mM}$ and 0.26 $\mathrm{nm} / \mathrm{mM}$. The optical sensors for $\mathrm{H}_{2} \mathrm{O}_{2}$ exhibit good analytical performance with low cost, convenient and sensitive detection. The CQDs may also be a promising candidate for biochemistry and biological applications.

\section{Acknowledgement}

The authors gratefully acknowledge the financial support provided to this study by the Ministry of Science and Technology of Taiwan under Grant No. MOST 1042221-E-131-029.

\section{References}

1. K. C. Lin, T. H. Tasi, S. M. Chen, Bioesns. Bioelectron., 26 (2010). 
2. A. Lobnik, M. Cajilakovic, Sens. Actuators B Chem., 74 (2001).

3. K. Kriz, M. Anderlung, D. Kriz, Bioesns. Bioelectron., 16 (2001).

4. K. F. Zhou, Y. H. Zhu, X. L. Yang, J. Luo, C. Z. Li, S. R. Luan, Electrochim. Acta, 55 (2010).

5. Z. H. Wang, F. Liu, X. Teng, C. X. Zhao, C. Lu, Analyst, 136 (2011).

6. S. A. G. Evans, J. M. Elliott, L. M. Andrews, P. N. Bartlett, P. J. Doyle, G. Denuault, Anal. Chem., 74 (2002).

7. K. M. Wang, J. Li, X. H. Yang, F. L. Shen, X. Wang, Sens. Actuators B Chem., 65 (2000).

8. S. Hanalka, J. M. Lin, M. Yamada, Anal. Chim. Acta., 426 (2001).

9. J. Yuan, W. Guo, E. Wang, Anal. Chem., 80 (2008).

10. A. N. Diaz, M. C. R. Peinado, M. C. T. Minguez, Anal. Chim. Acta., 363 (1998).

11. M. J. Zhou, Z. J. Diwu, N. PanchukVoloshina, R. P. Haugland, Anal. Biochem., 253 (1997).

12. Y. P. Sun, B. Zhou, Y. Lin, W. Wang, K. A. S. Fernando, P. Pathak, M. J. Meziani, B. A. Harruff, X. Wang, H. F. Wang, P. J. G. Luo, H. Yang, M. E. Kose, B. L. Chen, L. M. Veca, S. Y. Xie, J. Am. Chem. Soc., 128 (2006).

13. S. L. Hu, K. Y. Niu, J. Sun, J. Yang, N. Q. Zhao, X. W. Du, J. Mater. Chem., 19 (2009).

14. Q. L. Zhao, Z. L. Zhang, B. H. Huang, J. Peng, M. Zhang, D. W. Pang, Chem. Commun., 41 (2008).

15. L. Y. Zheng, Y. W. Chi, Y. Q. Dong, J. P. Lin, B. B. Wang, J. Am. Chem. Soc., 131 (2009).

16. J. G. Zhou, C. Booker, R. Y. Li, X. T. Zhou, T. K. Sham, X. L. Sun, Z. F. Ding, J. Am. Chem. Soc., 129 (2007).

17. L. Tian, D. Ghosh, W. Chen, S. Pradhan, X. J. Chang, S. W. Chen, Chem. Mat., 21 (2009).

18. S. H. Feng, R. R. Xu, Accounts Chem. Res., 34 (2001).

19. J. R. Lakowicz, Principles of Fluorescence Spectroscopy, 2nd ed; Kluwer Academic/Plenum Press, New York, 1999, Chapter 8 and 9. 